\title{
SISTEMAS DE MANEJO DO SOLO: SOJA [Glycine max (L.)] CONSORCIADA COM Brachiaria decumbens (STAPF) ${ }^{1}$
}

\author{
Rodrigo Gomes Pereira ${ }^{2}$, Abel Washingthon de Albuquerque ${ }^{2}$, Rafael de Oliveira Souza ${ }^{2}$, Alisson Douglas da Silva ${ }^{2}$, \\ João Paulo Araújo dos Santos², Emanuel da Silva Barros², Priscilla Vanúbia Queiroz de Medeiros ${ }^{3}$
}

\begin{abstract}
SOIL MANAGEMENT SYSTEMS: SOYBEAN [Glycine $\max ($ L.) ] INTERCROPPED WITH Brachiaria decumbens (STAPF)

The aim of this study was to evaluate the effects of different soil management systems on the soybean yield components intercropped or not with Brachiaria decumbens, in the coastal plateau of the Alagoas State, Brazil. For that, the 9350 Monsoy soybean was cultivated under conventional tillage, minimum tillage, and no-tillage. The experiment was carried out by using a split-plot randomized blocks design (with and without $B$. decumbens) and four replications. The variables analyzed were: 1) soybean: determination of phenological stages, chemical composition of plants, stand of plants, stem diameter, plant height, first pod insertion height, number of grains per pod, number of pods, number of grains per plant, mass of 1,000 grains, and yield; and 2) B. decumbens: chemical composition of plants and accumulation of dry matter, in five different sampling times. The soil management systems influenced the stand of plants and the concentration of $\mathrm{P}, \mathrm{Cu}, \mathrm{Fe}$, and $\mathrm{Zn}$, in soybean, besides $\mathrm{S}$, in $B$. decumbens. The no-tillage system showed higher grain and biomass yield for $B$. decumbens, under the edaphoclimatic conditions of Rio Largo, Alagoas State, Brazil.
\end{abstract}

KEY-WORDS: No-tillage; crop-livestock integrated system; minimum tillage.

\section{INTRODUÇÃO}

A soja [Glycine $\max (\mathrm{L}$.$) Merrill] é uma das$ culturas de maior importância econômica no mundo. Na safra 2007/2008, a produção brasileira de soja alcançou 60 milhões de toneladas, contribuindo com parcela significativa nas exportações, superando 17 bilhões de dólares, o que representou cerca de $10 \%$ das exportações do País (Conab 2008).

A produtividade da soja é definida pela interação da planta com o ambiente e o manejo. Altos ren-

\section{RESUMO}

Objetivou-se, com este trabalho, avaliar o efeito de diferentes sistemas de manejo do solo sobre os componentes de produção da soja cultivada solteira e em consórcio com B. decumbens, nos Tabuleiros Costeiros do Estado de Alagoas. Os tratamentos consistiram no cultivo da variedade de soja Monsoy 9350, nos sistemas preparo convencional do solo, cultivo mínimo e plantio direto. $\mathrm{O}$ delineamento experimental utilizado foi o em blocos casualizados, com parcelas subdivididas (com e sem $B$. decumbens), e quatro repetições. As variáveis analisadas foram: 1) cultura da soja: determinação dos estágios fenológicos, composição química das plantas, estande de plantas, diâmetro do colmo, altura de plantas, altura de inserção da primeira vagem, número de vagens por planta, número de grãos por vagem, número de grãos por planta, massa de 1.000 grãos e produtividade; e 2) $B$. decumbens: composição química das plantas, além do acúmulo de matéria seca, em cinco épocas de amostragens. Os sistemas de manejo do solo influenciaram o estande de plantas e a concentração de $\mathrm{P}, \mathrm{Cu}, \mathrm{Fe}$ e $\mathrm{Zn}$, na soja, além do S, na Brachiaria decumbens. O sistema plantio direto apresentou maior produtividade de grãos e produção de fitomassa de $B$. decumbens, nas condições edafoclimáticas de Rio Largo (AL).

PALAVRAS-CHAVE: Plantio direto; integração lavourapecuária; cultivo mínimo.

dimentos somente serão obtidos quando as condições supracitadas forem favoráveis, em todos os estádios de crescimento da cultura. Com isto, estudos sobre o manejo de solos se tornam fundamentais para aprimorar o rendimento desta cultura (Gilioli et al. 1995).

A soja é uma das culturas que melhor se adapta ao sistema plantio direto, sendo a principal cultura para compor os sistemas de rotação lavoura-pastagem, não só devido a aspectos econômicos, mas, também, por ser eficiente fixadora de nitrogênio atmosférico (Kluthcouski \& Stone 2003). Tal me-

1. Trabalho recebido em ago./2009 e aceito para publicação em jan./2011 (nº registro: PAT 6981/ DOI 10.5216/pat.v41i1.6981).

2. Universidade Federal de Alagoas, Centro de Ciências Agrárias, Rio Largo, AL, Brasil.

E-mails: rgpereira2005@hotmail.com, awa.albuquerque@hotmail.com,rafaelsouza_68@hotmail.com, alissondouglas7@hotmail.com, jotap20_3@hotmail.com,manosbjfa@hotmail.com.

3. Universidade Federal Rural do Semiárido, Departamento de Ciências Vegetais, Mossoró, RN, Brasil.

E-mail: pris_medeiros85@hotmail.com. 
canismo pode proporcionar fixação de $100-160 \mathrm{~kg}$ de $\mathrm{N}$ por hectare, os quais podem beneficiar outras culturas sucessoras (Mascarenhas et al. 2001, Mercante 2003).

O consórcio de culturas produtoras de grãos e forrageiras tropicais é possível graças ao diferencial no tempo e no espaço, no acúmulo de biomassa entre as espécies. As Brachiarias apresentam-se como grandes produtoras de fitomassa total e residual, apresentando boa palatabilidade e alta relação $\mathrm{C} / \mathrm{N}$, que tornam esta espécie uma boa opção para compor sistemas de rotação lavoura-pastagem (Menezes \& Leandro 2004, Noce et al. 2008).

O consórcio entre soja e braquiária apresenta alguns desafios, devido ao menor poder competitivo da cultura com a braquiária e dificuldades na colheita (Kluthcouski \& Aidar 2003, Oliveira Júnior 2006). Estes autores, entretanto, acreditam que manejos de aplicação de herbicidas ou semeadura da braquiária, em pós-emergência da soja, e o uso de cultivares de porte médio a alto e precoces, com maior altura de inserção da primeira vagem, poderão viabilizar este sistema.

Diante do exposto, este trabalho objetivou avaliar os componentes de produção de soja e Brachiaria decumbens, submetidas a diferentes sistemas de manejo do solo, sob as condições edafoclimáticas dos Tabuleiros Costeiros do Estado de Alagoas.

\section{MATERIAL E MÉTODOS}

O experimento foi desenvolvido no ano agrícola de 2007, na Área Experimental do Campus Delza Gitaí, pertencente ao Centro de Ciências Agrárias da Universidade Federal de Alagoas (9'29'45"S, $35^{\circ} 49^{\prime} 54^{\prime \prime} \mathrm{W}$ e altitude de $165 \mathrm{~m}$, com 3\% de declividade). $\mathrm{O}$ solo onde as parcelas experimentais foram instaladas foi classificado como Latossolo Amarelo coeso distrófico (Embrapa 2006). A região apresenta clima quente e úmido, totais pluviométricos anuais elevados (1.500-2.000 mm), com período chuvoso concentrado no outono-inverno, quando a precipitação equivale a $70 \%$ do total anual, e período seco na primavera-verão, apresentando déficits hídricos elevados (Souza et al. 2004).

As características químicas do solo, à profundidade de 0-0,20 m, amostradas antes da instalação do experimento, foram: $\mathrm{pH}$ em água: 4,82; MO: $35 \mathrm{~g} \mathrm{dm}^{-3}$; $\mathrm{P}$ (Mehlich): $35 \mathrm{~g} \mathrm{dm}^{-3}$; e $\mathrm{H}+\mathrm{Al}^{+3}, \mathrm{~K}^{+}$,
$\mathrm{Ca}^{+2}+\mathrm{Mg}^{+2}$ e T: $5,1 \mathrm{cmol}_{\mathrm{c}} \mathrm{dm}^{-3} ; 0,082 \mathrm{cmol}_{\mathrm{c}} \mathrm{dm}^{-3}$; $2,5 \mathrm{cmol}_{\mathrm{c}} \mathrm{dm}^{-3}$; e $7,71 \mathrm{cmol}_{\mathrm{c}} \mathrm{dm}^{-3}$, respectivamente. A saturação por base foi de $34 \%$ e, 90 dias antes do plantio, a área recebeu 3,5 $\mathrm{tha}^{-1}$ de calcário, com $80 \%$ de PRNT, objetivando-se elevar a saturação por bases para $70 \%$.

Os tratamentos consistiram no cultivo da variedade de soja Monsoy 9350 e de Brachiaria decumbens (STAPF), cultivar Brasilik, nos seguintes sistemas de preparo do solo: 1 - Sistema Convencional (SC); 2 - Cultivo Mínimo (CM); e 3 - Sistema Plantio Direto (SPD). As operações realizadas para caracterização de cada tratamento foram as seguintes: SPC - duas gradagens profundas e duas gradagens niveladoras; $\mathrm{CM}$ - uma gradagem profunda e uma subsolagem; (SPD) - dessecação da área coberta por pastagem de Brachiaria decumbens, por meio da aplicação do herbicidas de manejo Glifosato (concentração solúvel, ingrediente ativo $480 \mathrm{~g} \mathrm{~L}^{-1}$ ), aplicando-se dose equivalente a 5,0 $\mathrm{L} \mathrm{ha}^{-1}, 15$ dias antes da semeadura da soja, sobre a palhada. A área foi cultivada durante cinco anos consecutivos (2002-2007), sendo mantidos os mesmos sistemas de manejo do solo, sempre em consórcio ou não com B. decumbens.

O delineamento experimental utilizado foi o de blocos casualizados, com parcelas subdivididas (com e sem $B$. decumbens) e quatro repetições, tendo a área de cada parcela $80,0 \mathrm{~m}^{2}(5,0 \mathrm{~m}$ x 16,0 m). Cada sistema de preparo do solo correspondeu a uma parcela, sendo as subparcelas compostas pelos seguintes sistemas de cultivo: soja solteira, soja consorciada com Brachiaria decumbens e cultivo solteiro da Brachiaria decumbens.

A semeadura da soja foi realizada no dia 08/05/2007, utilizando-se semeadora pneumática de tração tratorizada, com três linhas espaçadas em 0,50 m, e 15-17 sementes. A cultivar de soja utilizada apresenta ciclo tardio (145 dias), hábito de crescimento determinado, altura média de 0,60-0,80 m e altura de inserção da primeira vagem de $0,16 \mathrm{~m}$. A população recomendada é de 250-330 mil plantas ha-1 (Abrasem 2003).

Por ocasião da semeadura, procedeu-se à inoculação das sementes com Bradyrhizobium japonicum (inoculante turfoso aplicado na dose equivalente a $0,6 \mathrm{~kg}$, para $40 \mathrm{~kg}^{-1}$ de sementes). Nesta ocasião, toda a área experimental recebeu $30 \mathrm{~kg} \mathrm{ha}^{-1}, 60 \mathrm{~kg} \mathrm{ha}^{-1}$ e $80 \mathrm{~kg} \mathrm{ha}^{-1}$ de $\mathrm{N}, \mathrm{P}_{2} \mathrm{O}_{5}$ e $\mathrm{K}_{2} \mathrm{O}$, respectivamente, aplicados no sulco de plantio, na 
forma de sulfato de amônio, superfosfato simples e cloreto de potássio.

$O$ cultivo de $B$. decumbens foi realizado manualmente, 25 dias após a emergência da soja $(08 / 06 / 2007)$, sendo semeada na entrelinha da soja, à profundidade de $3,0 \mathrm{~cm}$. A quantidade de sementes utilizada por hectare foi determinada por meio da divisão da constante 150 pelo valor cultural da semente (VC), fornecendo a quantidade de sementes de $B$. decumbens utilizadas $\left(\mathrm{kg} \mathrm{ha}^{-1}\right)$.

Durante o desenvolvimento da cultura, foram efetuadas três aplicações do inseticida $50 \mathrm{~g} \mathrm{~L}^{-1}$ Lambda-cyhalothrim, na dose de $150 \mathrm{~mL} \mathrm{ha}^{-1}$, aos 30, 45 e 65 dias após a emergência da soja, para o controle da largata-da-soja [Anticarsia gemmatalis (L.)] e percevejo-da-soja [Nezara viridula (L.)].

Após a emergência, foram marcadas cinco plantas por parcela, que apresentavam, aproximadamente, o mesmo porte e equidistância da área disponível para o seu desenvolvimento, objetivando-se a determinação dos seguintes estádios fenológicos: 1) vegetativo: VE (emergência) e VC (estádio de cotilédone), seguidos pelos estádios $\mathrm{V}_{1}, \mathrm{~V}_{2}, \mathrm{~V}_{3}$, até $\mathrm{V}_{\mathrm{n}}$ (onde " $\mathrm{n}$ " representa o número do último nó vegetativo formado); e 2) reprodutivo ( $\mathrm{R}$ ): $\mathrm{R}_{1}$ (início do florescimento, $50 \%$ das plantas com uma flor) até $\mathrm{R}_{9}$ (ponto de maturação de colheita), através da escala fenológica adaptada por Yorinori (1996).

As variáveis analisadas foram inserção da $1^{\text {a }}$ vagem; altura das plantas; diâmetro do colmo; estande de plantas; número de grãos por vagem; número de vagens totais por planta; número de grãos; massa de 1.000 grãos; produtividade de grãos, composição química das plantas de soja e $B$. decumbens, seguindo a metodologia da Embrapa (1997); e o número de dias acumulados para a determinação dos estádios fenológicos da cultivar Monsoy 9350.

As variáveis altura da inserção da primeira vagem e altura de plantas foram determinadas no início do processo de senescência, medindo-se, ao acaso, com o auxílio de uma régua, dez plantas por subparcela. Para determinação do diâmetro do colmo, utilizou-se um paquímetro graduado em milímetros. Foram avaliadas dez plantas por subparcela, no estádio de florescimento da soja. Para medição, considerou-se a haste principal, antes da primeira bifurcação.

A determinação do estande de plantas se deu por meio da contagem de todas as plantas da área útil de cada subparcela $(4,5 \mathrm{~m} \times 5,0 \mathrm{~m})$, com resultado extrapolado para um hectare. O número de vagens por planta foi determinado pela contagem, ao acaso, das vagens de dez plantas por subparcela. O número de grãos por vagem foi determinado a partir da seleção ao acaso de 10 plantas, para as quais se procedeu à contagem de todas as vagens das plantas, separando-as entre as classes.

O número de grãos por planta foi determinado mediante contagem dos grãos de dez plantas por subparcela, aleatoriamente. Para determinação da massa de 1.000 grãos, fez-se a contagem ao acaso de quatro repetições, que tiveram suas massas determinadas e ajustadas para $13 \%$ de umidade. Para a estimativa da produtividade, foram mensurados os grãos contidos na área útil de cada subparcela de $6,0 \mathrm{~m}^{2}(1,5 \mathrm{~m} \mathrm{x} 4,0 \mathrm{~m})$, mediante pesagem, expressa em toneladas por hectare, ajustada para $13 \%$ de teor de água.

Foram realizadas coletas de material vegetal da B. decumbens em cinco épocas, para determinação da fitomassa seca. Em cada época, foi coletado 1,0 $\mathrm{m}^{2}$ por subparcela, sempre em áreas diferentes. Os cortes foram realizados a $0,05 \mathrm{~m}$ do nível solo. As épocas das coletas foram: $1^{\mathrm{a}}$ coleta - na ocasião da colheita da soja; $2^{\mathrm{a}}$ coleta - quinze dias após a colheita da soja; $3^{\mathrm{a}}$ coleta - trinta dias após a colheita da soja; $4^{a}$ coleta - quarenta e cinco dias após a colheita da soja; e $5^{\text {a }}$ coleta - sessenta dias após a colheita da soja.

Durante o período de florescimento da soja, foram realizadas amostragens, para realização da análise de nutrientes. Para a $B$. decumbens, foram utilizados brotos novos e folhas verdes, provenientes da $3^{\text {a }}$ coleta. As plantas e folhas foram acondicionadas em estufa, a $70^{\circ} \mathrm{C}$, até atingirem peso constante. Em seguida, foram processadas em moinho e o material seco moído foi analisado no Laboratório de Nutrição Mineral de Plantas do Departamento de Recursos Naturais/Ciência do Solo da FCA/Unesp/Botucatu, para determinação dos teores de $\mathrm{N}, \mathrm{P}, \mathrm{K}, \mathrm{Ca}, \mathrm{Mg}, \mathrm{S}$, $\mathrm{B}, \mathrm{Cu}, \mathrm{Fe}, \mathrm{Mn}$ e Zn, de acordo com Embrapa (1997).

Os dados foram submetidos a análise de variância, sendo as médias comparadas pelo teste Tukey, a $5 \%$. Nos dados referentes às coletas de matéria seca de $B$. decumbens, foi realizada análise de variância e aplicação de regressão. Todas as análises foram realizadas com o auxílio do software Sisvar (Ferreira 2003).

\section{RESULTADOS E DISCUSSÃO}

Pelo teste Tukey, a 5\%, constatou-se que não houve diferença estatística entre os sistemas de ma- 
nejo do solo e as variáveis altura da planta; diâmetro do colmo; vagens com um, dois e três grãos; número de vagens; números de grãos; e massa de 1.000 grãos.

A altura das plantas variou de $40,55 \mathrm{~cm}$ a $45,40 \mathrm{~cm}$. Resultados superiores foram obtidos por Pelúzio et al. (2002), os quais, utilizando a mesma cultivar, obtiveram plantas com altura média de $60,3 \mathrm{~cm}$. Carvalho et al. (2004), cultivando soja em sucessão a adubos verdes, no primeiro ano de cultivo, obtiveram altura de plantas superiores às da presente pesquisa $(53,30 \mathrm{~cm}$ e $61,20 \mathrm{~cm}$, para os sistemas plantio direto e convencional, respectivamente).

A superioridade obtida por estes autores, para a mesma variável, pode ser justificada pelas condições ambientais e características inerentes à cultivar. De acordo com Monteiro (2009), cultivares de soja que não apresentam período juvenil longo podem apresentar crescimento vegetativo reduzido, quando cultivadas em regiões de baixa latitude.

Corroborando os resultados da presente pesquisa, Narimatsu (2004), cultivando soja nos sistemas convencional, mínimo e direto, não verificou diferença estatística para a variável diâmetro do colmo.

A variável inserção da primeira vagem sofreu redução significativa, quando a soja foi cultivada na presença da gramínea $B$. decumbens, em sistema convencional de preparo do solo $(11,77 \mathrm{~cm})$. Os demais sistemas de manejo avaliados para esta variável não foram influenciados pelo consórcio soja - B. decumbens. Segundo Yokomizo (1999), necessita-se de altura mínima de inserção da primeira vagem de $12 \mathrm{~cm}$, para realização da colheita mecânica da soja. No entanto, Lazarini (1995) sugere a realização de alguma adaptação para a colheita de plantas menores que $65,0 \mathrm{~cm}$, porém, com altura de inserção das primeiras vagens superior a $10,0 \mathrm{~cm}$, fato, este, que possibilita a colheita de soja mecanizada nos Tabuleiro Costeiros de Alagoas.

Gavotti et al. (2003), comparando o sistema de preparo SC ao SPD, não observaram diferença significativa para esta variável, contudo, obtiveram altura média de inserção da primeira vagem superior à do presente estudo (14,0 cm). Pelúzio et al. (2002) observaram altura média de inserção da primeira vagem de $14,4 \mathrm{~cm}$, para a mesma cultivar. A superioridade obtida por estes autores, para a mesma variável, pode ser justificada pelas características edáficas e época de semeadura.

Houve diferença significativa proporcionada pelos sistemas de manejo do solo sobre a variá- vel estande de plantas, onde o SPD, no consórcio soja - B. Decumbens, apresentou a maior média para esta variável: 275.500 plantas ha $^{-1}$ (Tabela 1). Este resultado corrobora os obtidos por Gaudêncio et al. (1990), os quais definiram a população de 280.000 plantas ha $^{-1}$ como sendo a melhor população de plantas de soja na região centro-sul do Paraná, instalada sob o sistema de manejo plantio direto.

A menor expressão da variável população de plantas, para os tratamentos $\mathrm{CM}$ e SC, pode ter ocorrido devido ao deslizamento da roda motriz da semeadora sobre o solo, no momento do plantio, o que justifica a menor população de plantas nestes tratamentos.

A presença de $B$. Decunbens, em consórcio com a soja, não influenciou, significativamente, a produtividade de grãos, dentro dos sistemas de manejo do solo aqui estudados (Tabela 1). Entretanto, entre os tratamentos avaliados, o sistema plantio direto consorciado com soja apresentou maior produtividade de grãos $\left(3.669,03 \mathrm{~kg} \mathrm{ha}^{-1}\right)$, ao passo que o sistema cultivo mínimo apresentou-se, estatisticamente, inferior aos demais tratamentos.

Pelúzio et al. (2002) apresentaram resultados similares aos obtidos na presente pesquisa, utilizando a mesma cultivar, obtendo produtividade média da ordem de $4.000 \mathrm{~kg} \mathrm{ha}^{-1}$. A menor produtividade de grãos obtida neste estudo pode ser explicada pela menor população de plantas. Estes resultados estão em conformidade com os obtidos por Urben Filho \& Souza (1993), Pelúzio et al. (2000) e Rocha et al. (2001).

Tabela 1. Avaliação agronômica da cultura da soja nos sistemas cultivo mínimo, preparo convencional e plantio direto, para soja solteira $(\mathrm{S} / \mathrm{B})$ e em consórcio $(\mathrm{C} / \mathrm{B})$ com Brachiaria decumbens (Rio Largo, AL, 2007).

\begin{tabular}{cccc}
\hline & $\begin{array}{c}\text { Sistema } \\
\text { convencional }\end{array}$ & $\begin{array}{c}\text { Cultivo } \\
\text { mínimo }\end{array}$ & $\begin{array}{c}\text { Sistema plantio } \\
\text { direto }\end{array}$ \\
\hline \multicolumn{4}{c}{ Inserção da primeira vagem $(\mathrm{cm})$} \\
\hline $\mathrm{C} / \mathrm{B}$ & $11,77 \mathrm{Aa}$ & $12,40 \mathrm{Aa}$ & $11,72 \mathrm{Aa}$ \\
$\mathrm{S} / \mathrm{B}$ & $13,07 \mathrm{Ab}$ & $11,65 \mathrm{Aa}$ & $11,90 \mathrm{Aa}$ \\
\hline \multicolumn{4}{c}{$\mathrm{Estande} \mathrm{de} \mathrm{plantas}\left(\mathrm{pl} \mathrm{ha}^{-1}\right)$} \\
\hline $\mathrm{C} / \mathrm{B}$ & $210000 \mathrm{Aa}$ & $180000 \mathrm{Aa}$ & $275500 \mathrm{Bb}$ \\
$\mathrm{S} / \mathrm{B}$ & $230000 \mathrm{Aa}$ & $193750 \mathrm{Aa}$ & $245000 \mathrm{Aa}$ \\
\hline \multicolumn{4}{c}{$\mathrm{Produtividade}\left(\mathrm{kg} \mathrm{ha}^{-1}\right)$} \\
\hline $\mathrm{C} / \mathrm{B}$ & $3177,66 \mathrm{Ba}$ & $2646,78 \mathrm{Aa}$ & $3669,03 \mathrm{Ba}$ \\
$\mathrm{S} / \mathrm{B}$ & $3234,70 \mathrm{Ba}$ & $2955,95 \mathrm{Aa}$ & $3379,20 \mathrm{Aa}$ \\
\hline
\end{tabular}

Médias seguidas pela mesma letra maiúscula, na linha, e médias seguidas da mesma letra minúscula, na coluna, não diferem entre si, pelo teste Tukey, a 5\%. 
Pauletti et al. (2003), após avaliar sucessões culturais e sistemas de manejo do solo, observaram superioridade do sistema plantio direto sobre o sistema convencional, quanto à produtividade. Kluthcouski et al. (2000) constataram que, nos consórcios de culturas anuais com espécies forrageiras, as culturas anuais apresentam grande performance de desenvolvimento inicial, exercendo, com isto, alta competição sobre as forrageiras, evitando-se, assim, redução significativa na produtividade de grãos.

Narimatsu (2004), cultivando soja nos sistemas de cultivo mínimo, preparo convencional e plantio direto, sobre a palhada de $B$. brizantha, observou maior produção de grãos para os sistemas com revolvimento de solo, atribuindo a estes a maior população de plantas.

Na Tabela 2, podem ser observados os dados referentes às análises dos macro e micronutrientes da cultura da soja. Foi possível verificar que os sistemas de manejo não influenciaram os teores foliares de $\mathrm{N}$, $\mathrm{K}, \mathrm{Ca}, \mathrm{Mg}, \mathrm{S}, \mathrm{B}$ e Mn.

Quanto aos teores de P, o SPD, com 4,30 $\mathrm{g} \mathrm{kg}^{-1}$, apresentou a maior média, quando comparado com o $\mathrm{SC}$, que apresentou $3,77 \mathrm{~g} \mathrm{~kg}^{-1}$, e o $\mathrm{CM}$, com $4,00 \mathrm{~g} \mathrm{~kg}^{-1}$. Do ponto de vista nutricional, podem-se observar teores considerados baixos para o N, em todos os tratamentos, e para o S, no sistema convencional, quando comparados aos sugeridos por Sfredo et al. (2001) e Kurihara (2004).

Os sistemas de manejo também influenciaram as concentrações de $\mathrm{Cu}, \mathrm{Fe}$ e $\mathrm{Zn}$. O SPD e SC não se diferenciaram, estatisticamente, entre si, apresentando os maiores valores de $\mathrm{Cu}\left(10,50 \mathrm{mg} \mathrm{kg}^{-1} \mathrm{e}\right.$ $10,00 \mathrm{mg} \mathrm{kg}^{-1}$, respectivamente) e $\mathrm{Zn}\left(71,75 \mathrm{mg} \mathrm{kg}^{-1} \mathrm{e}\right.$ $70,25 \mathrm{mg} \mathrm{kg}^{-1}$, respectivamente), quando comparados com o CM (Tabela 2). Por outro lado, o sistema plantio direto apresentou, nas plantas de soja analisadas, a menor concentração de $\mathrm{Fe}$, quando comparada com os demais tratamentos.

Os teores de $\mathrm{Cu}$ obtidos neste estudo, para o tratamento $\mathrm{CM}$, apresentaram níveis considerados baixos $\left(\mathrm{Cu}<6 \mathrm{mg} \mathrm{kg}^{-1}\right)$ para a cultura da soja, enquanto os teores de Mn apresentaram teores considerados baixos para todos os tratamentos $\left(15-20 \mathrm{mg} \mathrm{kg}^{-1}\right)$, para a cultura da soja (Sfredo et al. 2001).

Os teores de N, P, K, Ca, Mg, B, Cu, Fe, Mn e $\mathrm{Zn}$ não diferiram significativamente entre os tratamentos (Tabela 3), ou seja, os sistemas de manejo do solo não exerceram influência sobre os mecanismos de disponibilidade e consequente absorção pelas plantas de $B$. decumbens. Contudo, as concentrações de S variaram nas folhas analisadas, de acordo com o tipo de manejo do solo. Neste sentido, o sistema plantio direto apresentou a maior concentração, com $1,37 \mathrm{~g} \mathrm{~kg}^{-1}$, diferindo do sistema convencional $\left(1,07 \mathrm{~g} \mathrm{~kg}^{-1}\right)$, o qual não diferiu do cultivo mínimo $\left(1,22 \mathrm{~g} \mathrm{~kg}^{-1}\right)$.

Cruz (2007) apresentou valores inferiores aos obtidos neste experimento, para as concentrações de $\mathrm{N}$ e $\mathrm{P}\left(12,88 \mathrm{~g} \mathrm{~kg}^{-1}\right.$ e $2,15 \mathrm{~g} \mathrm{~kg}^{-1}$, respectivamente), cultivando milho em consórcio com $B$. decumbens. A superioridade para os teores de $\mathrm{Ne}$ e , obtida no presente estudo, pode ser atribuída à maior concentração de P, o qual, segundo Malavolta et al. (1997), apresenta influência direta na fixação biológica de nitrogênio.

Dos estádios fenológicos avaliados, para a cultivar Monsoy 9350 (Tabela 4), somente os estágios $\mathrm{VC} \mathrm{e} \mathrm{V}_{1}$ foram influenciados pelos sistemas de manejo do solo. O maior tempo requerido para o SPD atingir estes estádios pode ser explicado por Kluthcouski et al. (2000) e Yusuf et al. (1999), já que estes autores relatam que, quando a soja é cultivada sob sistema plantio direto, pode apresentar crescimento inicial reduzido, com plantas menos vigorosas, em relação ao preparo convencional.

Tabela 2. Análise dos macronutrientes e micronutrientes da soja, sob os sistemas plantio direto (SPD), cultivo mínimo (CM) e preparo convencional (SC) (Rio Largo, AL, 2007).

\begin{tabular}{|c|c|c|c|c|c|c|c|c|c|c|c|}
\hline \multirow{3}{*}{ Tratamentos } & \multicolumn{11}{|c|}{ Macronutrientes } \\
\hline & $\mathrm{N}$ & $\mathrm{P}$ & $\mathrm{K}$ & $\mathrm{Ca}$ & $\mathrm{Mg}$ & S & B & $\mathrm{Cu}$ & $\mathrm{Fe}$ & $\mathrm{Mn}$ & $\mathrm{Zn}$ \\
\hline & \multicolumn{6}{|c|}{$\left(\mathrm{g} \mathrm{kg}^{-1}\right)$} & \multicolumn{5}{|c|}{$-\left(\mathrm{mg} \mathrm{kg}^{-1}\right)$} \\
\hline SPD & $35,25 \mathrm{~A}$ & $4,30 \mathrm{~B}$ & $31,00 \mathrm{~A}$ & $14,75 \mathrm{~A}$ & $6,35 \mathrm{~A}$ & $2,02 \mathrm{~A}$ & $43,50 \mathrm{~A}$ & $10,50 \mathrm{~B}$ & $168,00 \mathrm{~A}$ & $17,00 \mathrm{~A}$ & $71,75 \mathrm{~B}$ \\
\hline $\mathrm{CM}$ & $34,75 \mathrm{~A}$ & $4,00 \mathrm{AB}$ & $32,00 \mathrm{~A}$ & $15,00 \mathrm{~A}$ & $6,27 \mathrm{~A}$ & $2,10 \mathrm{~A}$ & $51,00 \mathrm{~A}$ & $4,50 \mathrm{~A}$ & $256,50 \mathrm{~B}$ & $16,00 \mathrm{~A}$ & $53,50 \mathrm{~A}$ \\
\hline $\mathrm{SC}$ & $33,25 \mathrm{~A}$ & $3,77 \mathrm{~A}$ & $29,50 \mathrm{~A}$ & $14,25 \mathrm{~A}$ & $6,45 \mathrm{~A}$ & $1,92 \mathrm{~A}$ & $48,75 \mathrm{~A}$ & $10,00 \mathrm{~B}$ & $282,75 \mathrm{~B}$ & $17,25 \mathrm{~A}$ & $70,25 \mathrm{~B}$ \\
\hline DMS & 4,74 & 0,47 & 3,64 & 1,76 & 0,67 & 0,39 & 7,94 & 3,33 & 51,77 & 4,04 & 10,41 \\
\hline CV (\%) & 6,22 & 5,37 & 5,32 & 5,47 & 4,84 & 8,88 & 7,53 & 20,12 & 9,81 & 11,03 & 7,73 \\
\hline
\end{tabular}

Médias seguidas de letras diferentes, nas colunas, diferem, estatisticamente, entre si, pelo teste Tukey, a $5 \%$. 
Tabela 3. Análise de macronutrientes e micronutrientes de Brachiaria decumbens consorciada com soja, sob preparo convencional (SC), cultivo mínimo (CM) e sistema plantio direto (SPD) (Rio Largo, AL, 2007).

\begin{tabular}{|c|c|c|c|c|c|c|c|c|c|c|c|}
\hline \multirow{3}{*}{ Tratamentos } & \multicolumn{11}{|c|}{ Macronutrientes } \\
\hline & $\mathrm{N}$ & $\mathrm{P}$ & K & $\mathrm{Ca}$ & $\mathrm{Mg}$ & $\mathrm{S}$ & $\mathrm{B}$ & $\mathrm{Cu}$ & $\mathrm{Fe}$ & $\mathrm{Mn}$ & $\mathrm{Zn}$ \\
\hline & \multicolumn{6}{|c|}{$\longrightarrow\left(\mathrm{g} \mathrm{kg}^{-1}\right) \longrightarrow$} & \multicolumn{5}{|c|}{$\longrightarrow\left(\mathrm{mg} \mathrm{kg}^{-1}\right) \longrightarrow$} \\
\hline $\mathrm{SC}$ & $17,50 \mathrm{~A}$ & $3,40 \mathrm{~A}$ & $23,50 \mathrm{~A}$ & $3,19 \mathrm{~A}$ & $3,30 \mathrm{~A}$ & $1,07 \mathrm{~A}$ & $15,60 \mathrm{~A}$ & $4,50 \mathrm{~A}$ & $130,00 \mathrm{~A}$ & $13,75 \mathrm{~A}$ & $27,00 \mathrm{~A}$ \\
\hline $\mathrm{CM}$ & $18,25 \mathrm{~A}$ & $4,00 \mathrm{~A}$ & $22,50 \mathrm{~A}$ & $3,25 \mathrm{~A}$ & $4,02 \mathrm{~A}$ & $1,22 \mathrm{AB}$ & $14,25 \mathrm{~A}$ & $6,25 \mathrm{~A}$ & $132,75 \mathrm{~A}$ & $13,25 \mathrm{~A}$ & $26,75 \mathrm{~A}$ \\
\hline SPD & $17,50 \mathrm{~A}$ & $4,12 \mathrm{~A}$ & $24,00 \mathrm{~A}$ & $3,20 \mathrm{~A}$ & $3,90 \mathrm{~A}$ & $1,37 \mathrm{~B}$ & $17,25 \mathrm{~A}$ & $5,00 \mathrm{~A}$ & $142,75 \mathrm{~A}$ & $13,00 \mathrm{~A}$ & $29,50 \mathrm{~A}$ \\
\hline DMS & 3,29 & 0,85 & 3,82 & 1,25 & 0,88 & 0,29 & 4,79 & 2,31 & 22,65 & 2,63 & 5,61 \\
\hline CV (\%) & 8,55 & 10,18 & 7,56 & 17,75 & 10,90 & 11,22 & 14,50 & 20,33 & 7,73 & 9,10 & 9,32 \\
\hline
\end{tabular}

Médias seguidas de letras diferentes, nas colunas, diferem, estatisticamente, entre si, pelo teste Tukey, a 5\%.

Tabela 4. Quantidade de dias acumulados para determinação dos estádios fenológicos vegetativos (VE) e reprodutivos (R) da variedade de soja Monsoy 9350, cultivada sob os sistemas plantio direto (SPD), cultivo mínimo (CM) e preparo convencional (SC) (Rio Largo, AL, 2007).

\begin{tabular}{|c|c|c|c|c|c|c|c|c|c|c|c|c|}
\hline \multirow{3}{*}{ Tratamentos } & \multicolumn{12}{|c|}{ Estádios fenológicos } \\
\hline & $\mathrm{VE}$ & $\mathrm{VC}$ & $\mathrm{V}_{1}$ & $\mathrm{R}_{1}$ & $\mathrm{R}_{4}$ & $\mathrm{R}_{5.1}$ & $\mathrm{R}_{5.5}$ & $\mathrm{R}_{7.1}$ & $\mathrm{R}_{7.3}$ & $\mathrm{R}_{8.1}$ & $\mathrm{R}_{8.2}$ & $\mathrm{R}_{9}$ \\
\hline & \multicolumn{12}{|c|}{ (dias) } \\
\hline SPD & $6,00 \mathrm{~A}$ & $12,25 \mathrm{~B}$ & $14,75 \mathrm{~B}$ & $37,25 \mathrm{~A}$ & $51,25 \mathrm{~A}$ & $55,25 \mathrm{~A}$ & $82,25 \mathrm{~A}$ & $90,75 \mathrm{~A}$ & $98,00 \mathrm{~A}$ & $101,25 \mathrm{~A}$ & $105,25 \mathrm{~A}$ & $113,75 \mathrm{~A}$ \\
\hline $\mathrm{CM}$ & $6,00 \mathrm{~A}$ & $10,00 \mathrm{~A}$ & $13,00 \mathrm{~A}$ & $36,75 \mathrm{~A}$ & $50,75 \mathrm{~A}$ & $54,75 \mathrm{~A}$ & $81,50 \mathrm{~A}$ & $90,50 \mathrm{~A}$ & $97,50 \mathrm{~A}$ & $100,75 \mathrm{~A}$ & $104,75 \mathrm{~A}$ & $112,25 \mathrm{~A}$ \\
\hline $\mathrm{SC}$ & $6,00 \mathrm{~A}$ & $10,00 \mathrm{~A}$ & $13,00 \mathrm{~A}$ & $37,00 \mathrm{~A}$ & $50,75 \mathrm{~A}$ & $55,00 \mathrm{~A}$ & $81,75 \mathrm{~A}$ & $91,00 \mathrm{~A}$ & $97,75 \mathrm{~A}$ & $100,75 \mathrm{~A}$ & $104,75 \mathrm{~A}$ & $112,25 \mathrm{~A}$ \\
\hline DMS & 0,00 & 0,63 & 0,82 & 0,97 & 0,73 & 0,73 & 1,57 & 1,32 & 0,92 & 1,17 & 0,90 & 2,27 \\
\hline $\mathrm{CV}(\%)$ & 0,00 & 2,59 & 2,69 & 1,19 & 0,65 & 0,61 & 0,87 & 0,66 & 0,43 & 0,53 & 0,39 & 0,91 \\
\hline
\end{tabular}

Médias seguidas de letras diferentes, nas colunas, diferem, estatisticamente, entre si, pelo teste Tukey, a 5\%.

De acordo com a Abrasem (2003), a cultivar Monsoy 9350 necessita de 61 dias para ir da emergência à floração e de 145 dias para atingir a maturação. No entanto, nas condições de cultivo de Rio Largo (AL), houve redução dos subperíodos de 24 e 32 dias, referentes à floração e maturação, respectivamente.

Marchiori et al. (1999) e Peixoto (1999) observaram redução no ciclo de cultivares de soja, em função do plantio, em épocas do ano onde ocorre menor fotoperíodo. Este fato pode ser justificado devido à influencia do ambiente na floração da soja, a qual responde ao nictoperíodo ou à duração da noite (Garner \& Allard 1920, Borthwick et al. 1952).

De acordo com Monteiro (2009), a utilização de cultivares que apresentam período juvenil longo resulta em perído vegetativo mais longo de plantas de soja, o que favorecerá o florescimento tardio, em condições de noites longas, como no caso da presente pesquisa.

$\mathrm{Na}$ Tabela 5, encontram-se os resultados das análises referentes à matéria seca de $B$. decumbens, cultivada solteira e em consórcio com soja, sob os sistemas de manejo do solo SC, CM e SPD.
Observa-se que houve comportamento linear crescente na produção de matéria seca da gramínea, porém, ao se observar o crescimento da Brachiaria solteira e em consórcio, verifica-se menor crescimento nos sistemas em consórcio. Este decréscimo no crescimento da Brachiaria se justifica pela forte competição exercida pela soja, principalmente pelo sombreamento (Kluthcouski et al. 2000).

Observa-se que, a partir dos 30 dias após a colheita da soja, o sistema plantio direto obteve o maior rendimento entre os tratamentos (Tabela 5). Estes resultados estão de acordo com Klepker \& Anghinoni (1995), que apontam os sistemas conservacionistas de manejo como aqueles que melhoram as características químicas, físicas e biológicas do solo, de maneira a modificar a distribuição e morfologia das raízes das plantas subsequentes, com reflexos no crescimento da parte aérea, interferindo, consequentemente, na produtividade.

Narimatsu (2004) obteve menor produção de matéria seca de Brachiaria brizantha no tratamento sem mobilização do solo, em relação aos tratamentos com revolvimento do solo. 
Tabela 5. Produção de matéria seca $\left(\mathrm{kg} \mathrm{ha}^{-1}\right)$ de Brachiaria decumbens em cultivo solteiro (Test.) e consórciada com soja (*) coletada em cinco períodos após a colheita da soja, sob os sistemas de preparo do solo convencional (SC), cultivo mínimo (CM) e plantio direto (SPD) (Rio Largo, AL, 2007).

\begin{tabular}{|c|c|c|c|c|c|c|c|}
\hline \multirow{2}{*}{$\begin{array}{l}\text { Sistema de } \\
\text { manejo }\end{array}$} & \multicolumn{5}{|c|}{ Dias após a colheita da soja } & \multirow{2}{*}{ Regressão } & \multirow{2}{*}{$\mathrm{R}^{2}$} \\
\hline & 0 & 15 & 30 & 45 & 60 & & \\
\hline $\mathrm{SC}^{\text {Test. }}$ & 645,40 & 769,79 & 891,70 & 1102,08 & 1331,40 & $y=170,43 x^{* *}+436,79$ & 0,97 \\
\hline $\mathrm{CM}^{\text {Test. }}$ & 571,05 & 789,23 & 1003,05 & 1126,88 & 1261,85 & $y=171,92 x^{* *}+434,64$ & 0,98 \\
\hline SPD ${ }^{\text {Test. }}$ & 458,13 & 788,98 & 1113,20 & 1253,22 & 1405,85 & $\mathrm{y}=235,97 \mathrm{x} *+295,97$ & 0,96 \\
\hline $\mathrm{SC}^{*}$ & 159,38 & 233,15 & 336,11 & 515,52 & 616,80 & $\mathrm{y}=119,72 \mathrm{x} * *+13,023$ & 0,98 \\
\hline $\mathrm{CM}^{*}$ & 141,29 & 220,27 & 342,29 & 467,60 & 751,22 & $\mathrm{y}=146,72 \mathrm{x} * *-55,619$ & 0,94 \\
\hline SPD* & 123,28 & 250,51 & 389,08 & 542,04 & 828,40 & $\mathrm{y}=170,18 \mathrm{x} * *-83,868$ & 0,97 \\
\hline
\end{tabular}

Test. B. decumbens em cultivo solteiro. * B. decumbens consorciada com soja. ** Significativo pelo teste F, a $1 \%$.

\section{CONCLUSÕES}

1. Os sistemas de manejo do solo influenciam na altura de inserção da primeira vagem, estande de plantas, produtividade de grãos e concentração de $\mathrm{P}, \mathrm{Cu}, \mathrm{Fe}$ e $\mathrm{Zn}$, na soja Monsoy 9350, e S, quando se utiliza Brachiaria decumbens.

2. O sistema plantio direto apresenta maior produtividade de grãos e produção de fitomassa de B. decumbens, sob as condições edafoclimáticas de Rio Largo (AL).

\section{REFERÊNCIAS}

ASSOCIAÇÃO BRASILEIRA DE SEMENTES E MUDAS (Abrasem). Cultivares de soja habilitadas no zoneamento agrícola: ano safra 2003/2004. Diário Oficial da União, Brasília, DF, 29 ago. 2003. Seção 1, p. 12.

BORTHWICK, H. A.; HENDRICKS, S. B.; PARKER, M. $\mathrm{V}$. The reaction controlling floral initiation. Proceedings of the National Academy of Sciences, Washington, DC, v. 38, n. 11, p. 929-934, 1952.

CARVALHO, M. A. C. et al. Soja em sucessão a adubos verdes no sistema de plantio direto e convencional em solo de Cerrado. Pesquisa Agropecuária Brasileira, Brasília, DF, v. 39, n. 11, p. 1141-1148, nov. 2004.

COMPANHIA NACIONAL DE ABASTECIMENTO (Conab). Acompanhamento da safra brasileira: grãos: intenção de plantio, primeiro levantamento, outubro de 2008. 2008. Disponível em: <http//www.conabweb/ download/safra/estdo_safra.pdf $>$. Acesso em: 15 mar. 2009.

CRUZ, S. C. S. Milho e Brachiaria decumbens em sistemas de integração lavoura-pecuária. $2007.78 \mathrm{f}$. Dissertação (Mestrado em Agronomia)-Faculdade de Ciências Agronômicas, Universidade Estadual Paulista, Botucatu, 2007.
EMPRESA BRASILEIRA DE PESQUISA AGROPECUÁRIA (Embrapa). Serviço Nacional de Levantamento e Conservação do Solo. Manual de métodos de análises químicas de solos. Rio de Janeiro: EmbrapaCNPS, 1997.

EMPRESA BRASILEIRA DE PESQUISA AGROPECUÁRIA (Embrapa). Centro Nacional de Pesquisa de Solos. Sistema brasileiro de classificação de solos. Rio de Janeiro: Embrapa, 2006.

FERREIRA, D. F. Programa Sisvar: versão 4.6. Lavras: UFLa, 2003.

GARNER, W. W.; ALLARD, H. A. Effect of the relative length of day and night and other factors of the environment on growth and reproduction in plants. Journal of Agricultural Research, Washington, DC, v. 48, n. 7, p. 553-606, 1920.

GAUDÊNCIO, C. A. A. et al. População de plantas de soja no sistema de semeadura direta para o centro-sul do Estado do Paraná. Comunicado Técnico do Centro Nacional de Pesquisa de Soja, Londrina, n. 47, p. 1-4, set. 1990.

GAVotti, F. S. M.; Centurion, M. A. P. C.; CENTURION, J. F. Comportamento da soja, cultivar IAC FOSCARIM 31, em quatro sistemas de preparo do solo. In: REUNIÃO DE PESQUISA DE SOJA DA REGIÃO CENTRAL DO BRASIL, 25., 2003, Uberaba. Resumos... Uberaba: Embrapa Soja/Epamig/Fundação Triângulo, 2003. p. 254-255.

GILIOLI, J. L. et al. Soja: série 100. Cristalina: FT Sementes, 1995. (Boletim técnico, 3).

KLEPKER, D.; ANGHINONI, I. Características físicas e químicas do solo afetadas por métodos de preparo e modos de aplicação. Revista Brasileira de Ciência do Solo, Campinas, v. 19, n. 3, p. 395-401, 1995.

KLUTHCOUSKI, J.; AIDAR, H. Implantação, condução e resultados obtidos com o Sistema Santa Fé. In: KLUTHCOUSKI, J.; STONE, L. F.; AIDAR, H. (Eds.). Integração lavoura-pecuária. Santo Antônio de Goiás: Embrapa Arroz e Feijão-CNPAF, 2003. p. 407-441. 
KLUTHCOUSKI, J. et al. Sistema Santa Fé - tecnologia Embrapa: integração lavoura-pecuária pelo consórcio de culturas anuais com forrageiras em áreas de lavoura nos sitemas direto e convencional. Santo Antônio de Goiás: Embrapa Arroz e Feijão, 2000. (Circular técnica, 38).

KLUTHCOUSKI, J.; STONE, L. F. Manejo sustentável dos solos dos Cerrados. In: KLUTHCOUSKI, J.; STONE, L. F.; AIDAR, H. Integração lavoura-pecuária. Santo Antônio de Goiás: Embrapa, 2003. p. 61-104.

KURIHARA, C. H. Demanda de nutrientes pela soja e diagnose de seu estado nutricional. 2004. $101 \mathrm{f}$. Tese (Doutorado em Solos e Nutrição de Plantas)-Universidade Federal de Viçosa, Viçosa, 2004.

LAZARINI, E. Avaliação das características agronômicas $e$ análises nutricionais de genótipos de soja semeadas em diferentes épocas, em Jaboticabal - SP. 1995. 197 f. Tese (Doutorado em Fitotecnia)-Faculdade de Ciências Agrárias e Veterinárias, Universidade Estadual Paulista "Júlio de Mesquita Filho", Jaboticabal, 1995.

MALAVOLTA, E.; VITTI, G. C.; OLIVEIRA, S. A. Avaliação do estado nutricional de plantas: princípios e aplicações. 2. ed. Piracicaba: Potafos, 1997.

MARCHIORI, L. F. S. et al. Desempenho vegetativo de cultivares de soja em épocas normal e safrinha. Scientia Agricola, Piracicaba, v. 56, n. 2, p. 383-390, abr./jun. 1999.

MASCARENHAS, H. A. A. et al. Efeito residual de leguminosas sobre o rendimento fisico e econômico da cana-planta. Campinas: Instituto Agronômico, 2001. (Boletim científico, 32).

MENEZES, L. A. S.; LEANDRO, W. M. Avaliação de espécies de coberturas do solo com potencial de uso em sistema de plantio direto. Pesquisa Agropecuária Tropical, Goiânia, v. 34, n. 3, p. 173-180, 2004.

MERCANTE, F. M. Fixação biológica de nitrogênio na cultura da soja? Como se beneficiar? In: ENCONTRO DE PLANTIO DIRETO NO CERRADO, 7., 2003, Sorriso. Anais... Cuiabá: Ed. UFMT, 2003. p. 25-29.

MONTEIRO, J. E. B. A. Agrometeorologia dos cultivos: o fator meteorológico na produção agrícola. Brasília, DF: INMET, 2009.

NARIMATSU, K. C. P. Plantio direto de soja sobre Brachiaria brizantha no sistema integração agriculturapecuária. 2004. 73 f. Dissertação (Mestrado em Agronomia)Universidade Estadual Paulista, Ilha Solteira, 2004.

NOCE, M. A. et al. Influência da palhada de gramíneas forrageiras sobre o desenvolvimento da planta de milho e das plantas daninhas. Revista Brasileira de Milho e Sorgo, Sete Lagoas, v. 7, n. 3, p. 265-278, 2008.

OLIVEIRA JÚNIOR, P. R. Produtividade de cultivares de soja em consórcio com braquiária, subdoses de herbicida e uso de potássio em cobertura. 2006. 57 f. Dissertação (Mestrado em Agronomia)-Faculdade de Ciências Agrárias, Universidade de Marília, Marília, 2006.

PAULETTI, V. et al. Rendimento de grãos de milho e soja em uma sucessão cultural de oito anos sob diferentes sistemas de manejo de solo e de culturas. Ciência Rural, Santa Maria, v. 33, n. 3, p. 491-495, maio/jun. 2003.

PEIXOTO, C. P. Análise de crescimento e rendimento de três cultivares de soja em três épocas de semeadura e três densidades de plantas. 1999. 151 f. Tese (Doutorado em Fitotecnia)-Escola Superior de Agricultura "Luiz de Queiroz”, Universidade de São Paulo, Piracicaba, 1999.

PELÚZIO, J. M. et al. Densidade e espaçamento de plantas de soja variedade Conquista em Gurupi, TO. Bioscience Journal, Uberlândia, v. 16, n. 1, p. 3-13, 2000.

PELÚZIO, J. M. et al. Comportamento de duas cultivares de soja em diferentes populações de plantas, sob condições de várzea irrigada, no sul do Estado do Tocantins. Revista Agricultura Tropical, Cuiabá, v. 6, n. 1, p. 69-80, 2002.

ROCHA, R. N. C. et al. Comportamento de cultivares de soja em diferentes populações de plantas, em Gurupi, Tocantins. Revista Ceres, Viçosa, v. 48, n. 279, p. 529537, 2001.

SFREDO, G. J.; BORKERT, C. M.; KLEPKER, D. $O$ cobre $(\mathrm{Cu})$ na cultura da soja: diagnose foliar. In: REUNIÃO DE PESQUISA DE SOJA DA REGIÃO CENTRAL DO BRASIL, 23., 2001, Londrina. Resumos... Londrina: Embrapa Soja, 2001, p. 95. (Documentos, 157).

SOUZA, J. L. de et al. Análise da precipitação pluvial e temperatura do ar na região do Tabuleiro Costeiro de Maceió, AL, período de 1972-2001. Revista Brasileira de Agrometeorologia, Santa Maria, v. 12, n. 1, p. 131141, 2004.

URBEN FILHO, G.; SOUZA, P. I. M. Manejo da cultura da soja sob Cerrado: época, densidade e profundidade de semeadura. In: ARANTES, N. E.; SOUZA, P. I. M. (Eds.). Cultura da soja nos Cerrados. Piracicaba: Potafos, 1993. p. 267-298.

YOKOMIZO, G. K. Interação genótipos $x$ ambientes em topocruzamentos de soja tipo alimento com tipo grão. 1999. 170 f. Tese (Doutorado em Genética e Melhoramento de Plantas)-Escola Superior de Agricultura Luiz de Queiroz, Universidade de São Paulo, Piracicaba, 1999.

YORINORI, J. T. Cancro da haste da soja: epidemiologia e controle. Londrina: Embrapa-CNPSO, 1996. (Circular técnica, 14).

YUSUF, R. I.; SIEMENS, J. C.; BULLOCK, D. G. Growth analysis of soybean under no-tillage and conventional tillage systems. Agronomy Journal, Madison, v. 91, n. 6, p. 928-933, 1999. 